\title{
Using atmospheric model output to simulate the meteorological tsunami response to Tropical Storm Helene (2000)
}

\author{
J. V. Mecking, ${ }^{1,2}$ C. T. Fogarty, ${ }^{3}$ R. J. Greatbatch, ${ }^{1,2}$ J. Sheng, ${ }^{1}$ and D. Mercer ${ }^{4}$ \\ Received 1 January 2009; revised 16 June 2009; accepted 23 July 2009; published 6 October 2009.
}

[1] In the fall of both 1999 and 2000, unexpected "rapid tides" occurred along the coast of the Avalon Peninsula of Newfoundland. These rapid tides have been linked to the passing of Tropical Storm Jose (1999) and Tropical Storm Helene (2000) over the Grand Banks. Here we examine the dynamic ocean response to Tropical Storm Helene (2000) using a barotropic shallow water ocean model forced by atmospheric pressure and surface winds derived from a simulation of Helene using a dynamical model of the atmosphere. The ocean model is able to capture the main features of the observed response at the coast of Newfoundland as seen in the available tide gauge data. Results show that the simulated sea level response at the coast is driven by a combination of wind stress and atmospheric pressure forcing, the former generally dominating. An exception is Conception Bay, Newfoundland, where the response is captured mainly by atmospheric pressure forcing. Offshore near the edge of the Grand Banks, atmospheric pressure and wind stress forcing are equally important. The wind-forced response depends on the divergence of the surface wind stress and hence on the structure of the storm in the atmospheric model simulation. Sensitivity studies show the importance of having a small time interval (on the order of minutes) at which the atmospheric forcing is supplied to the ocean model and show the importance of the location of the storm track.

Citation: Mecking, J. V., C. T. Fogarty, R. J. Greatbatch, J. Sheng, and D. Mercer (2009), Using atmospheric model output to simulate the meteorological tsunami response to Tropical Storm Helene (2000), J. Geophys. Res., 114, C10005, doi:10.1029/2009JC005290.

\section{Introduction}

[2] Atlantic Canadian coastal waters (see Figure 1) are occasionally affected by tropical cyclones. These storms can have a devastating effect in the form of a storm surge and/or meteorological tsunami. (In this paper, a "meteorological tsunami" refers to tsunami-like waves that are remotely generated by atmospheric pressure and surface wind fields.) In some cases the tropical cyclone does not even have to make landfall to have a coastal impact. In the falls of both 1999 and 2000, there were eyewitness reports from several locations on the southeastern coast of Newfoundland that the water level was rising and falling with periods of tens of minutes and amplitudes at some locations of perhaps several meters [Mercer et al., 2002]. Local weather conditions were fair, with only light to moderate winds, and there were no reports of seismic activity that could have produced these waves. On both occasions, there were fast moving tropical cyclones passing over the Grand Banks of Newfoundland:

\footnotetext{
${ }^{1}$ Department of Oceanography, Dalhousie University, Halifax, Nova Scotia, Canada.

${ }^{2}$ Leibniz Institute of Marine Sciences at University of Kiel (IFMGEOMAR), Kiel, Germany.

${ }^{3}$ Canadian Hurricane Center, Environment Canada, Dartmouth, Nova Scotia, Canada.

${ }^{4}$ Environment Canada, Dartmouth, Nova Scotia, Canada.

Copyright 2009 by the American Geophysical Union. 0148-0227/09/2009JC005290\$09.00
}

Tropical Storm Jose (1999) and Tropical Storm Helene (2000). These storms were too far offshore for their direct influence to be felt at the coast of Newfoundland, and there was no mention of the possibility of the wave events in the hurricane information bulletins issued by Environment Canada. It was later argued by Mercer et al. [2002] that Jose and Helene were responsible for the observed wave events. Helene was chosen over Jose for the present study on the basis of the availability of data.

[3] Tropical storm Helene moved across the Grand Banks at a speed close to the shallow water gravity wave speed, $\sqrt{g H}$, where $g$ is the gravitational acceleration and $H$ is the water depth, making it an interesting example for studying the ocean response. Mercer et al. [2002], who did not consider wind forcing, used an idealized atmospheric pressure field and the observed storm track of Tropical Storm Helene to force a barotropic shallow water ocean model and found a model response at the coast corresponding in time to that of the observations. The correspondence in time between the model response at the coast and the observations suggests that the wave events were indeed caused by Tropical Storm Helene. However, the forcing used by Mercer et al. [2002] was idealized, and wind forcing was omitted. Here we reexamine the wave events associated with Helene by driving an ocean model using surface atmospheric pressure and wind fields derived from an atmospheric model simulation. The ocean model results are then compared with the available tide gauge data, and the separate influences of surface atmospheric 
Tropical Storm Helene (2000)

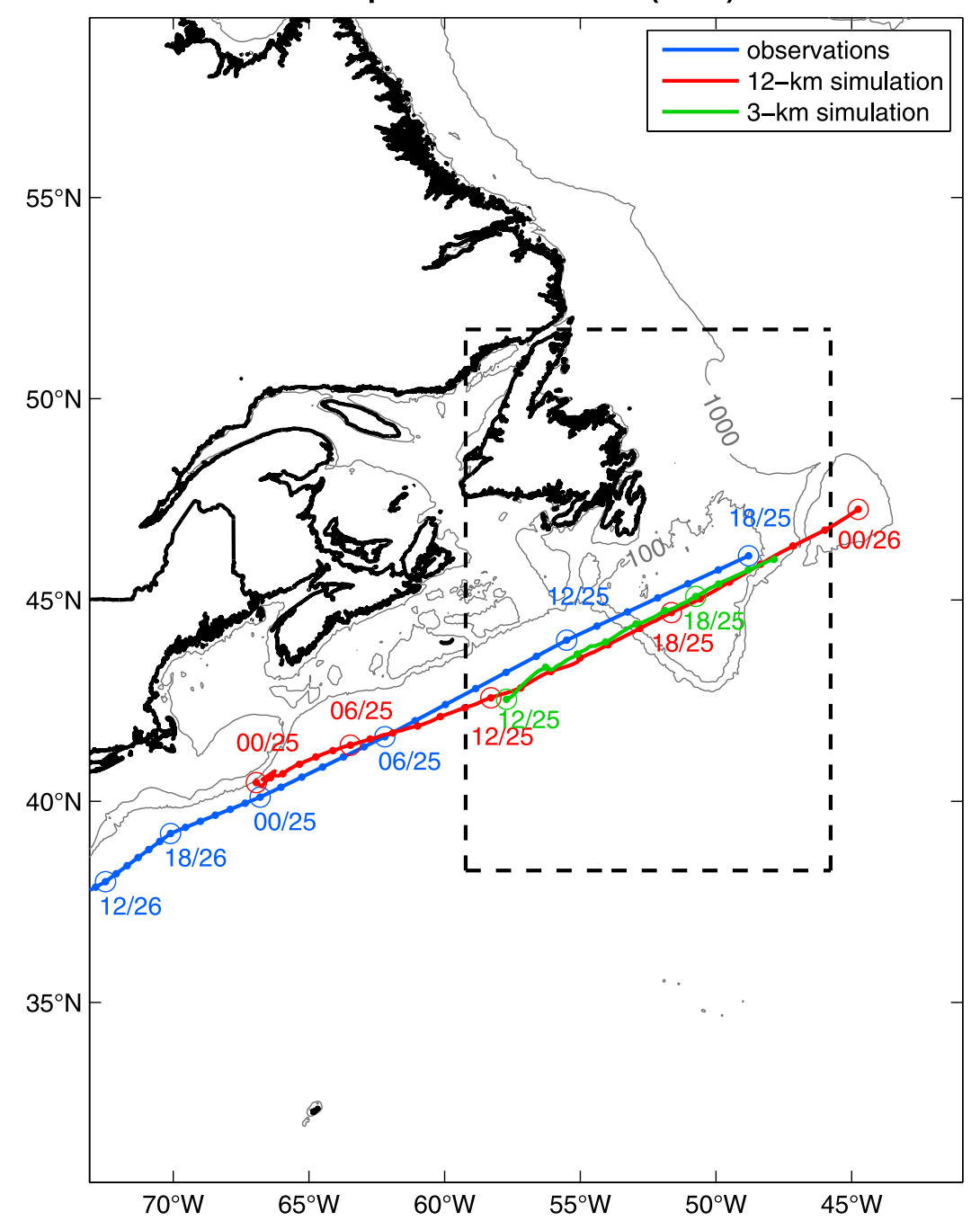

Figure 1. The 12-km model domain with the $3-\mathrm{km}$ model domain marked by the dashed box. The blue line shows the storm track from the observations of Tropical Storm Helene [Blake and Avila, 2000] with time given in hours and days (HH/DD UTC). The red line shows the storm track from the $12-\mathrm{km}$ model simulation, and the green line shows the storm track from the 3-km model simulation. The $100-$ and $1000-\mathrm{m}$ bathymetry contours are shown along with the coastline.

pressure and wind forcing are determined. We demonstrate an important role for wind forcing, which, in turn, depends on the structure of the wind field in the atmospheric model simulation.

[4] Environment Canada currently uses a depth-averaged ocean model to forecast storm surges. The ocean model is forced every hour using atmospheric pressure and wind fields at the sea surface taken from the global environmental multiscale (GEM) numerical weather prediction model. This modeling system has been successful at simulating the storm surge associated with large, slow moving extratropical systems [Bobanović et al., 2006]. However, for real-time forecasts of Atlantic Canadian storm surges from tropical cyclone events, the Canadian Hurricane Center currently uses basic conceptual principles and the experience of forecasters rather than the operational storm surge system. The reason is that for small intense systems, like Helene, the Canadian GEM model often does not resolve the storm (see Figure 2).
[5] The present work is motivated by the need for an operational coupled atmosphere-ocean modeling system capable of predicting storm surges and meteorological tsunamis for Atlantic Canada. We use a linear, barotropic ocean model based on the storm surge model developed by Bobanovic and Thompson [2001]. The atmospheric forcing is taken from a simulation of Tropical Storm Helene that uses the Mesoscale Compressibility Community (MC2) model [Benoit et al., 1997] together with a vortex insertion method [cf. Fogarty et al., 2007]. The latter uses data available from the National Hurricane Center and satellite imagery to create a vortex specified by intensity, size, and initial position, which is then inserted into the atmospheric fields as the initial condition for the MC2 model. The impact of vortex insertion is apparent from Figure 2, which shows a comparison, at a time when Helene was over the Grand Banks of Newfoundland, between the analysis used for the operational GEM forecast model and the 12-km MC2 model with vortex insertion $18 \mathrm{~h}$ into the model simulation. It is clear that the 


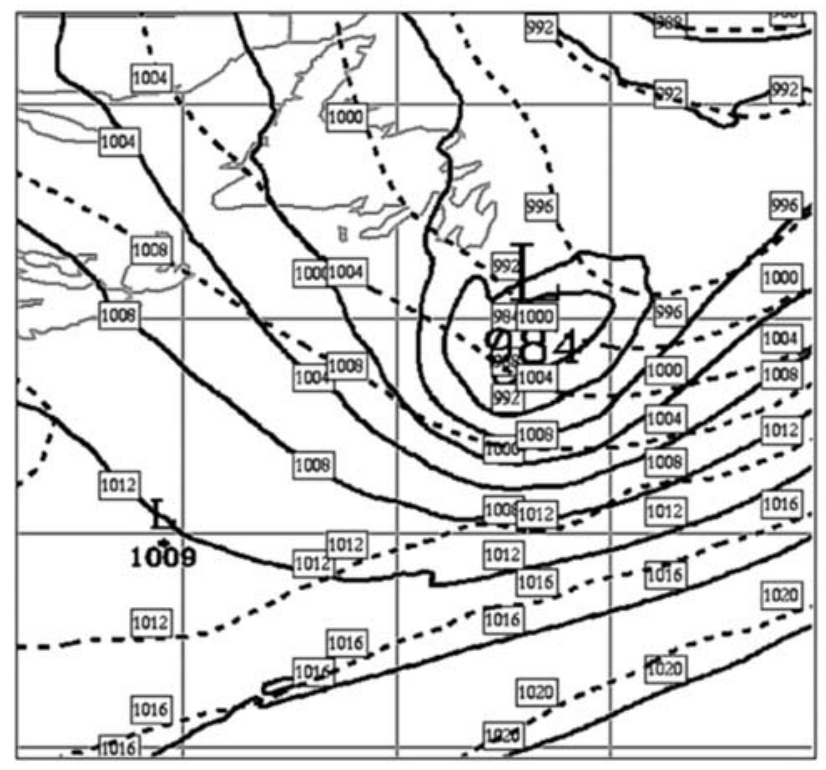

Figure 2. A comparison between the surface pressure field $18 \mathrm{~h}$ into the $12-\mathrm{km}$ MC2 model simulation with vortex insertion (solid lines) and the analysis for the operational GEM forecast model (dashed lines) at a time when Helene was over the Grand Banks of Newfoundland.

vortex is completely missing from the GEM analysis. The importance of vortex insertion has been shown previously by Fogarty et al. [2006], when simulating Hurricane Juan (2003), and Fogarty et al. [2007], when simulating Hurricane Michael (2000).

[6] The structure of the paper is as follows. We begin with a synoptic history of Tropical Storm Helene in section 2 and a description of the numerical ocean model in section 3 . The atmospheric model results are presented in section 4 , and the ocean model results are presented in section 5 along with a comparison with the available tide gauge data and a brief sensitivity study. Section 6 provides a summary and conclusions.

\section{Synoptic History of Tropical Storm Helene (2000)}

[7] Tropical storm Helene (2000) developed from a tropical wave off the western coast of Africa on 10 September 2000. It became a tropical depression on 15 September 2000 and later a tropical storm on 21 September 2000 over the southeastern Gulf of Mexico [Blake and Avila, 2000]. Helene first made landfall near Fort Walton Beach, Florida, and then passed over several of the southern American states before reemerging over the Atlantic Ocean from the coast of North Carolina. Once over the ocean, Helene reintensified and moved east-northeast off the coast of Nova Scotia and toward the Grand Banks of Newfoundland. The storm passed over the Grand Banks on 25 September 2000, with a mean translation speed of $26 \mathrm{~m} \mathrm{~s}^{-1}$ (Figure 1).

\section{The Ocean Model}

[8] The ocean model used in this study was originally developed to investigate sea level variability in the Gulf of Saint Lawrence and the Scotian Shelf from local and remote wind forcing [Bobanović and Thompson, 2001]. The model was then further modified by Mercer et al. [2002] and reprogrammed for the present study in FORTRAN 90 to improve its efficiency.

\subsection{Governing Equations}

[9] The ocean circulation model integrates the linear shallow water equations forced by atmospheric pressure and wind stress. The nontidal sea level variations, $\eta$, can be decomposed into two parts, the sea level changes associated with the inverse barometer effect given by $\eta_{a}=-p_{a}^{\prime} / \rho g$ and the adjusted sea level, $\eta^{\prime}$ [Gill, 1982]. Here $\rho$ is the density of the ocean water, $g$ is the gravitational acceleration, and $p_{a}^{\prime}$ is the atmospheric pressure perturbation. The total sea level is $\eta=\eta_{a}+\eta^{\prime}$. The governing equations in Cartesian coordinates are

$$
\begin{gathered}
\frac{\partial u}{\partial t}-f v=-g \frac{\partial \eta^{\prime}}{\partial x}+\frac{\tau^{x}}{\rho H}-\frac{r u}{H}, \\
\frac{\partial v}{\partial t}+f u=-g \frac{\partial \eta^{\prime}}{\partial y}+\frac{\tau^{y}}{\rho H}-\frac{r v}{H}, \\
\frac{\partial \eta^{\prime}}{\partial t}+\frac{\partial(H u)}{\partial x}+\frac{\partial(H v)}{\partial y}=-\frac{\partial \eta_{a}}{\partial t},
\end{gathered}
$$

where $(u, v)$ are the eastward and northward components of the depth-averaged current, $H(x, y)$ is the local water depth, $\left(\tau^{x}, \tau^{y}\right)$ is the wind stress, $f$ is the Coriolis parameter, and $r$ is the bottom friction parameter. The inverse barometer effect represented by $\eta_{a}$ is the equilibrium sea level height change owing to perturbations in the atmospheric pressure field. Perturbations in the atmospheric pressure field of $10 \mathrm{hPa}$ give a sea level rise due to the inverse barometer effect of $\sim 10 \mathrm{~cm}$.

[10] To understand the important dynamics of the meteorological tsunami, we can ignore the bottom friction and the Coriolis terms (although these are included in the model simulations that follow), both of which are reasonable approximations for the time scales of interest and away from the immediate nearshore region. Equations (1)-(3) can be rewritten in terms of the adjusted sea level, $\eta^{\prime}$ as

$$
\frac{\partial^{2} \eta^{\prime}}{\partial t^{2}}-\vec{\nabla} \cdot\left(c^{2} \vec{\nabla} \eta^{\prime}\right)=-\frac{\vec{\nabla} \cdot \vec{\tau}}{\rho}-\frac{\partial^{2} \eta_{a}}{\partial t^{2}},
$$

where $\vec{\nabla}=\hat{i}(\partial / \partial x)+\hat{j}(\partial / \partial y)$ and $\vec{\tau}$ is the wind stress vector. Equation (4) demonstrates that if wind stress is important, then it is the horizontal divergence of the surface wind stress that matters for determining the adjusted sea level response to the storm. In particular, if the wind stress field is axisym-

Table 1. List of the Experiments Used in the Storm Track Sensitivity Study ${ }^{\mathrm{a}}$

\begin{tabular}{ccccc}
\hline Experiment & MSLP $(\mathrm{hPa})$ & Latitude $\left({ }^{\circ} \mathrm{N}\right)$ & Longitude $\left({ }^{\circ} \mathrm{W}\right)$ & $\mathrm{R}_{15}$ \\
\hline HCR & 993 & 40.1 & 66.8 & 200 \\
HN1 & 993 & $\mathbf{4 0 . 4}$ & 66.8 & 200 \\
HN2 & 993 & $\mathbf{4 0 . 7}$ & 66.8 & 200 \\
\hline
\end{tabular}

${ }^{\mathrm{a}}$ The differences between the HCR and the other ensemble members are in bold type. The latitude and longitude refer to the position of the synthetic vortex that is inserted into the atmospheric model, and $\mathrm{R}_{15}$ refers to the radius of the $15 \mathrm{~m} \mathrm{~s}^{-1}$ winds. 

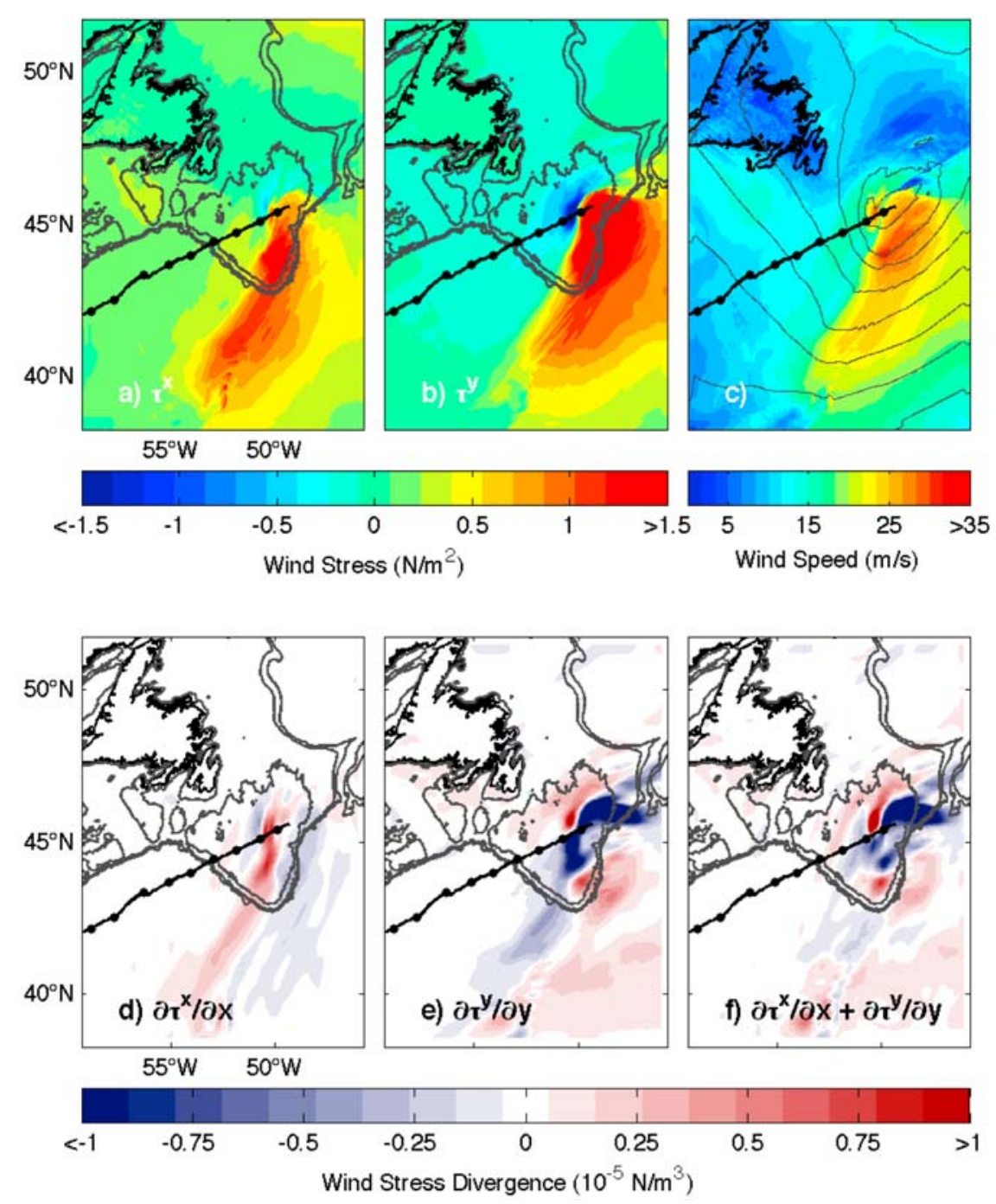

Figure 3. The (a) eastward and (b) northwardwind stress components at $10.5 \mathrm{~h}$, (c) the wind speed and isobars for the surface pressure at 4-hPa intervals, the contributions of the (d) eastward and (e) northward wind stress to (f) the divergence of the wind stress. All plots are based on the 3-km atmospheric model and show the model storm track in black with dots indicating the hourly position. Also shown are the 100-, 500-, and 1000-m isobaths (dark gray, except in Figure 3c). The wind stress divergence has been averaged over a $60 \mathrm{~km}$ by $60 \mathrm{~km}$ box centered on each grid point.

metric about the storm center, no response in adjusted sea level can be excited by the wind stress.

\subsection{Ocean Model Setup and Forcing}

[11] The numerical code solves equations (1)-(3) recast to spherical coordinates on a latitude-longitude grid using an Arakawa $\mathrm{C}$ grid and the Flather boundary condition on the open boundaries as described by Carter and Merrifield [2007]. The initial sea state is assumed to be at rest with zero adjusted sea level (the total sea level is given by the inverse barometer effect). The model uses the same computational grid as the $3-\mathrm{km}$ grid of the atmospheric circulation model to be described in section 4 and a time step of $5 \mathrm{~s}$, unless otherwise stated.

[12] Wind stress is converted from the wind velocity taken from the atmospheric circulation model on the basis of

$$
\vec{\tau}=\rho_{\mathrm{air}} C_{D}\left|\overrightarrow{U_{10}}\right| \overrightarrow{U_{10}}
$$

where $\rho_{\text {air }}$ is the density of air, $C_{D}$ is the drag coefficient, and $\overrightarrow{U_{10}}$ is the 10 -m wind velocity. The empirically derived bulk formula suggested by Large and Pond [1981] is used for the drag coefficient:

$$
C_{D} \times 10^{3}=\left\{\begin{array}{lr}
1.2 & 0 \leq\left|\overrightarrow{U_{10}}\right|<11 \mathrm{~m} \mathrm{~s}^{-1} \\
0.49+0.065\left|\vec{U}_{10}\right| & 11 \leq\left|\overrightarrow{U_{10}}\right| \leq 27 \mathrm{~m} \mathrm{~s}^{-1}
\end{array}\right.
$$

Most of the existing knowledge of values for the drag coefficient comes from measurements of wind speeds $<25 \mathrm{~m} \mathrm{~s}^{-1}$ [e.g., Large and Pond, 1981; Yelland and Taylor, 1996; Donelan et al., 1997]. Estimates of the drag coefficient in tropical storms were made using dropsonde data by Powell et al. [2003], and their study suggests capping of the drag coefficient for high winds. The capped value for $C_{D}$ was estimated by Donelan et al. [2004] to be about 


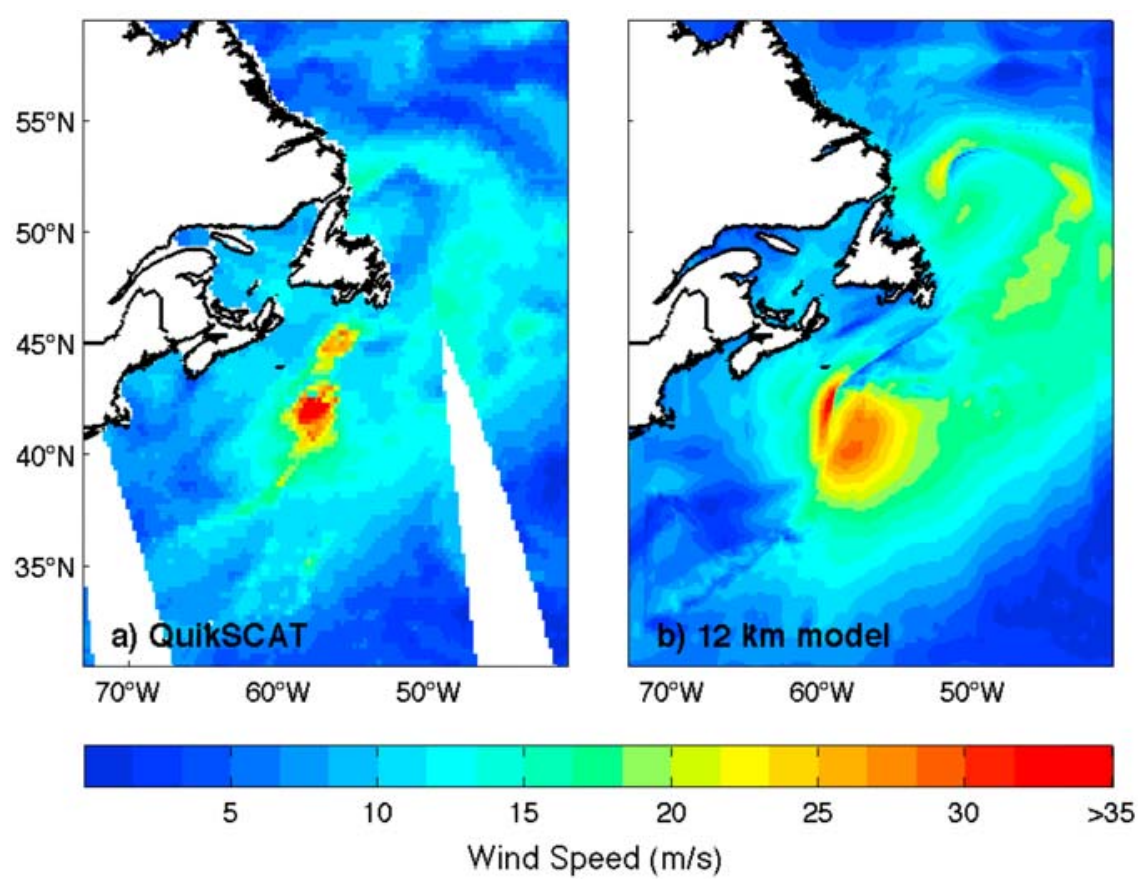

Figure 4. (a) Ten-meter wind speeds derived from QuikSCAT scatterometer data for 0925 UTC 25 September 2000. (b) Wind speed from the lowest computational level (40 m) at 1200 UTC 25 September 2000 from the simulation of Tropical Storm Helene on the 12-km atmospheric model grid.

$2.25 \times 10^{-3}$. In this study the drag coefficient is set to $2.25 \times 10^{-3}$ for wind speeds above $27 \mathrm{~m} \mathrm{~s}^{-1}$.

\section{Atmospheric Forcing}

\subsection{Atmospheric Circulation Model}

[13] The atmospheric model is the Mesoscale Compressible Community (MC2) model developed by the Recherche Prévision Numérique and Université du Québec à Montréal [Benoit et al., 1997]. The MC2 model solves the fully compressible Euler equations using a semi-implicit, semiLagrangian time scheme. Lateral boundary conditions for the model are supplied by the Canadian Meteorological Centre analysis fields on a $\sim 28-\mathrm{km}\left(0.25^{\circ}\right)$ piloting domain. The model setup is based on that used by Fogarty et al. [2006] and has two components, $\mathrm{a} \sim 12-\mathrm{km}\left(0.108^{\circ}\right)$ grid onto which the storm vortex is inserted and an inner component with a finer $\sim 3-\mathrm{km}\left(0.027^{\circ}\right)$ grid nested within the $12-\mathrm{km}$ grid. The fine grid component uses an atmospheric time step of $30 \mathrm{~s}$. Output from the $3-\mathrm{km}$ model is saved at 5 -min intervals and used to drive the ocean model. The $12-\mathrm{km}$ model simulations of Tropical Storm Helene cover the region between $30.5^{\circ} \mathrm{N}$ and $59.5^{\circ} \mathrm{N}$ and between $73.1^{\circ} \mathrm{W}$ and $40.9^{\circ} \mathrm{W}$ (Figure 1). The $3-\mathrm{km}$ model grid covers the region between $38.3^{\circ} \mathrm{N}$ and $51.7^{\circ} \mathrm{N}$ and between $59.2^{\circ} \mathrm{W}$ and $45.8^{\circ} \mathrm{W}$ (Figure 1, dashed box).

[14] To represent the storm vortex in the initial conditions of the MC2 model, a synthetic vortex is inserted onto the $12-\mathrm{km}$ grid. For best results with this technique, the vortex should be inserted while the storm is still in the tropical state before the extratropical transition (ET) process has begun. This is because the synthetic vortex is moist symmetric (although it does have an asymmetric wind field owing to storm forward motion), whereas moisture symmetry is not a trait of ET. The parameters used to create the vortex are the minimum sea level pressure, the position of the storm, the radius of $15 \mathrm{~m} \mathrm{~s}^{-1}$ winds $\left(\mathrm{R}_{15}\right)$, and the speed of the storm motion, which are all parameters available when preparing forecasts of tropical cyclones. The use of synthetic vortex insertion with the MC2 model has been shown to be successful with a number of storms [Fogarty et al., 2006, 2007]. The MC 2 model, with synthetic vortex insertion, is currently run experimentally on a real-time basis at the Canadian Hurricane Center when storms are active.

[15] Winds from the lowest computational level and atmospheric pressure at mean sea level are used as the forcing for the ocean model. The lowest computational level in the MC2 model is $40 \mathrm{~m}$ from the mean sea level. Fogarty et al. [2006] have shown that the $40-\mathrm{m}$ winds produced by the MC2 model are more indicative of observed $10-\mathrm{m}$ winds in the storm than are the $10-\mathrm{m}$ winds extrapolated from the MC2 results. For this reason the $40-\mathrm{m}$ wind fields given by the MC2 model are used to represent the $10-\mathrm{m}$ winds in this study.

\subsection{Atmospheric Model Results}

[16] The synthetic vortex representing Tropical Storm Helene was inserted onto the $12-\mathrm{km}$ grid at 0000 UTC 25 September 2000 at $40.1^{\circ} \mathrm{N}$ and $66.9^{\circ} \mathrm{W}$, using the best available values for the storm intensity and the initial position taken from Blake and Avila [2000] (in Table 1, this is experiment HCR). The model was integrated for $9 \mathrm{~h}$ on the $12-\mathrm{km}$ grid before the $3-\mathrm{km}$ grid was initiated.

[17] Initially, the storm in the $12-\mathrm{km}$ model simulation moves slower than the observed storm. Within the first $9 \mathrm{~h}$, the position of the modeled storm lags behind the observed storm by $3 \mathrm{~h}$ but moves at a similar speed thereafter. The $3-\mathrm{km}$ simulated storm moves at a more rapid translational speed than the $12-\mathrm{km}$ storm such that the modeled storm lags the observed storm by $2 \mathrm{~h}$ at 1800 UTC 25 September 2000 . Furthermore, the storm in the $12-\mathrm{km}$ model simulation is too 

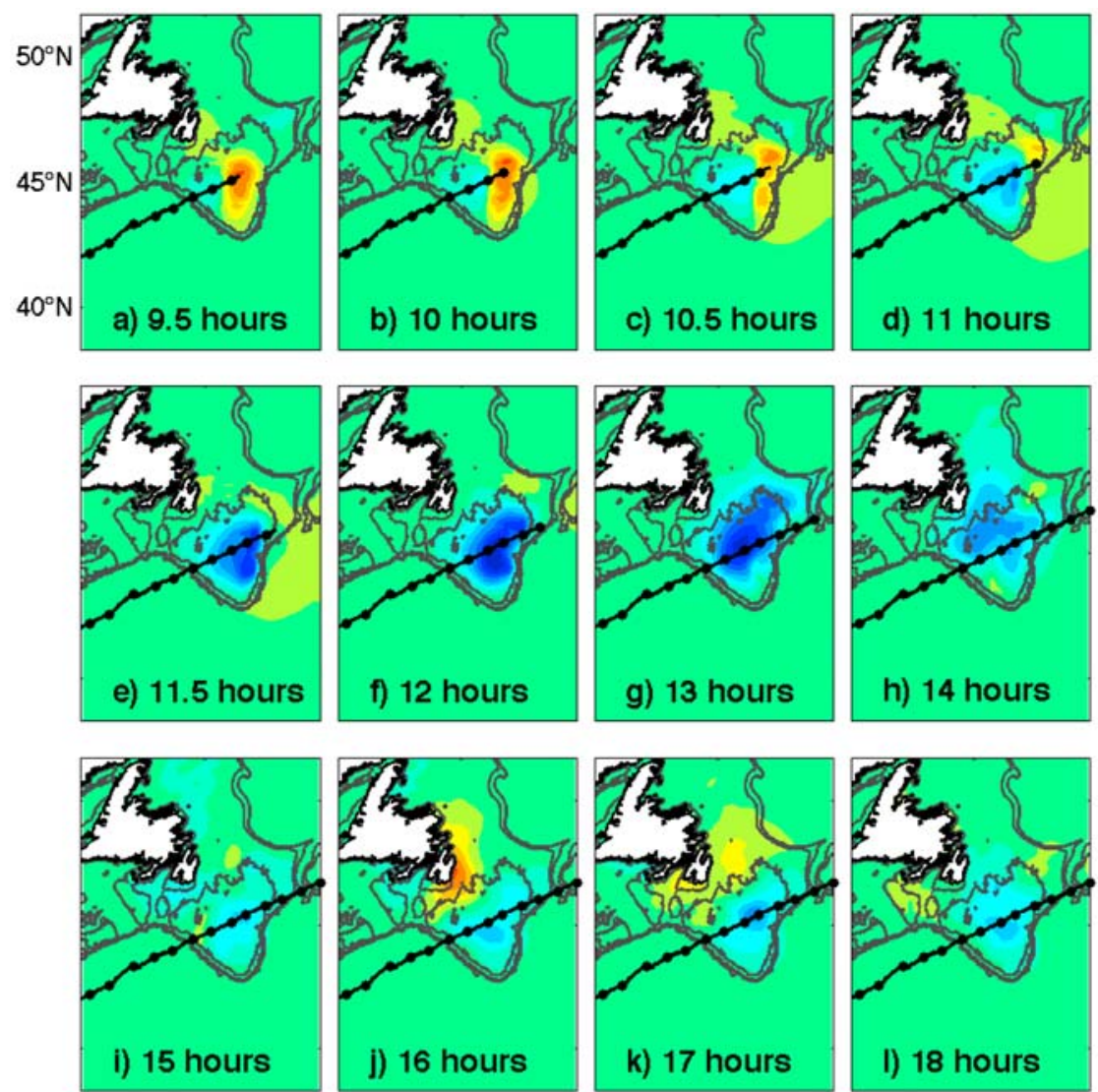

$55^{\circ} \mathrm{W} 50^{\circ} \mathrm{W}$

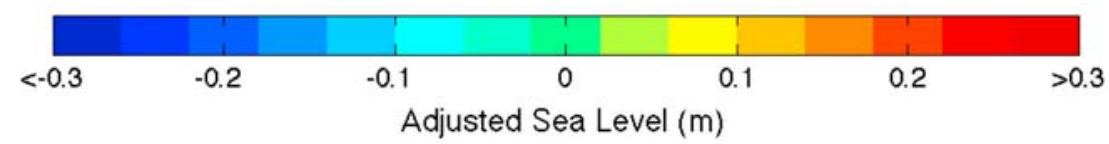

Figure 5. Time series of model-calculated adjusted sea level forced by both atmospheric pressure and surface wind forcing. The solid black line represents the storm track with hourly storm positions marked by solid dots, and the dark gray lines give the 100,500 , and $1000 \mathrm{~m}$ depth contours. The time is given in hours from simulation start time. Note that the separation time between the plots is $0.5 \mathrm{~h}$ between Figures $5 \mathrm{a}-5 \mathrm{f}$ and $1 \mathrm{~h}$ between Figures $5 \mathrm{f}-51$.

far north initially (by $1.3^{\circ}$ ), but by 1200 UTC 25 September, the storm's position is farther south (by $1.8^{\circ}$ ) than the observed one. Consequently, the $3-\mathrm{km}$ run was initialized with a storm a bit too far south. The location of the storm track for both the $12-\mathrm{km}$ simulation and the $3-\mathrm{km}$ simulation is too far south by $\sim 0.4^{\circ}$ latitude $(\sim 50 \mathrm{~km})$ from 1200 UTC 25 September 2000 onward (see Figure 1), an issue addressed in section 5.2.

[18] The 3-km model simulation is characterized by an elongated pressure pattern in the along-track direction with closed isobars indicating a storm center and a large area of strong winds on the right side of the storm where the winds exceed $30 \mathrm{~m} \mathrm{~s}^{-1}$ (see Figure 3c). Figure 3 also shows the eastward $\left(\tau^{x}\right)$ and northward $\left(\tau^{y}\right)$ components of the wind stress, together with the divergence of the wind stress and the contributions from $\tau^{x}$ and $\tau^{y}$, at $10.5 \mathrm{~h}$ from the start of the $3-\mathrm{km}$ model run (hereafter $10.5 \mathrm{~h}$ ). As noted when discussing equation (4), it is the divergence of the wind stress that is important for the sea level response. As can be seen from Figure 3, perhaps surprisingly, it is the northward component of the wind stress that matters most for determining the divergence in the case of Helene. It is also clear from the isobars shown in Figure 3c that geostrophy is not a good approximation for determining the wind field and hence the stress. This is because the time scale associated with the passage of the storm is short compared to the geostrophic adjustment time (i.e., a day) and also indicates the importance of having a dynamical model to determine the wind field and hence the stress. A frontal feature, which is common with storms that undergo ET, is apparent in the wind stress fields to the southwest of the storm, with strong southwesterly winds ahead of the front and much weaker winds in its rear. However, the wind stress divergence is dominated by the region of strong convergence near the storm center with a weaker area of divergence just to the east, with the contribution for the eastward and northward wind stress components tending to cancel along the front itself.

[19] A QuikSCAT overpass sampled Tropical Storm Helene at 0925 UTC 25 September 2000 (Figure 4a) at a position before the storm was fully present on the $3-\mathrm{km}$ grid. A comparison is therefore made with the $12-\mathrm{km}$ atmospheric model results at 1200 UTC 25 September 2000, when the 

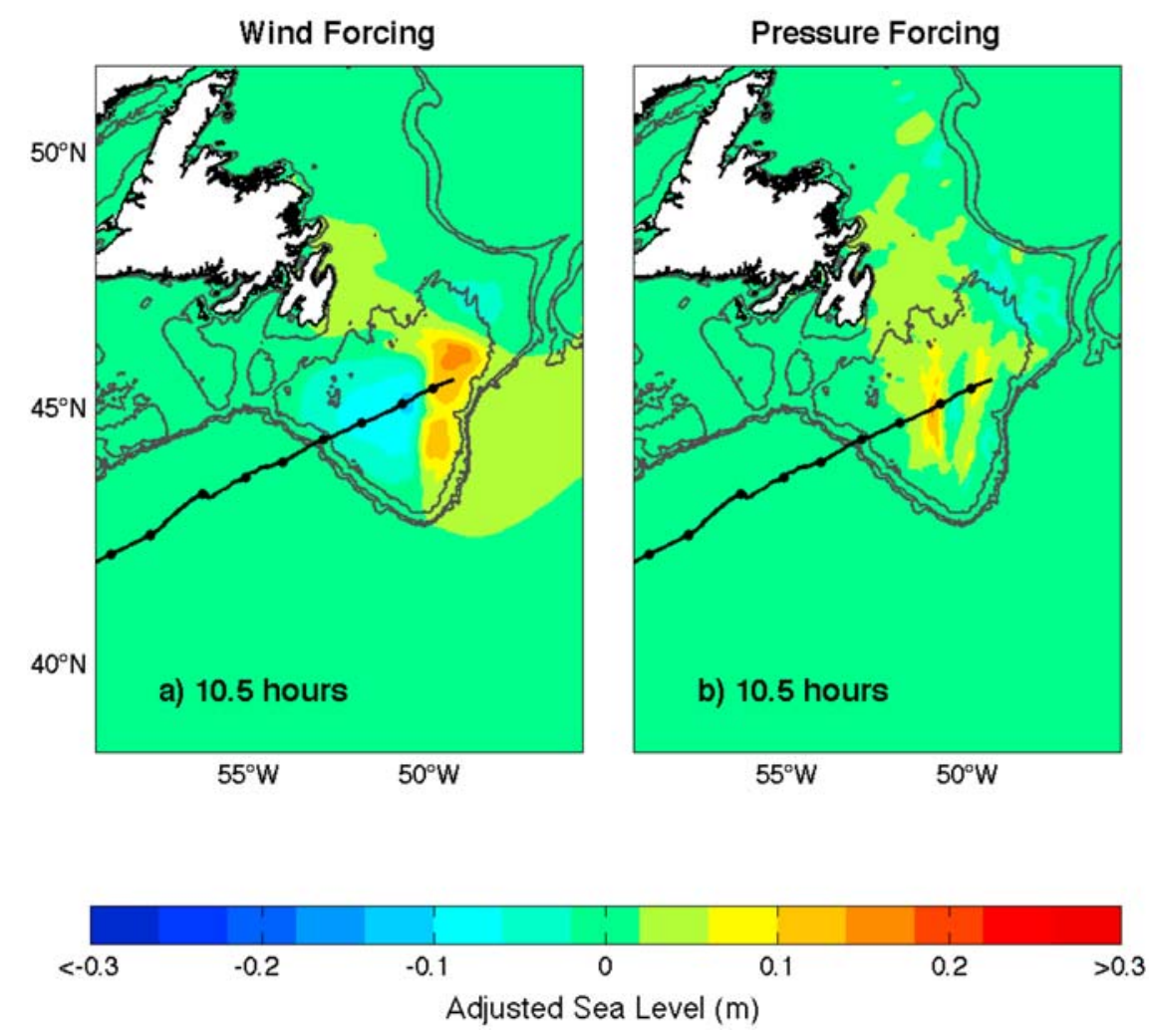

Figure 6. Model-calculated adjusted sea level at $10.5 \mathrm{~h}$ driven by (a) atmospheric wind forcing only and (b) pressure forcing only. The solid black line represents the storm track with hourly storm positions marked by solid dots, and the dark gray lines denote the 100-, 500-, and 1000-m depth contours. The time is given in hours from simulation start time.

modeled storm was closest in position to the observed storm in the QuikSCAT image (Figure 4b). The QuikSCAT image, which has $25-\mathrm{km}$ resolution, shows two areas of high winds in the storm, the larger one to the right of the storm with winds exceeding $30 \mathrm{~m} \mathrm{~s}^{-1}$ and another smaller one in the front left quadrant of the storm track with wind speeds also up to $30 \mathrm{~m} \mathrm{~s}^{-1}$. Comparing the model with QuikSCAT wind fields, the hindcast storm on the 12-km grid shows the same two areas of high winds but with the latter displaced to the rear left quadrant. On the $3-\mathrm{km}$ grid the modeled storm is dominated by the large area of strong winds to the right of the storm track (Figure 3c), with little evidence of the region of high winds to the left of the storm track. It should be noted, however, that we are only able to plot the wind speed for the $3-\mathrm{km}$ model at later times than shown in Figure $4 \mathrm{~b}$. It is also clear from Figure $4 \mathrm{~b}$ that the $12-\mathrm{km}$ model captures the large-scale environment seen in the QuikSCAT image including the feature to the northeast of Newfoundland, although the latter appears more strongly in the model than in the image. Given the crudity of the initialization procedure for the atmospheric model (i.e., vortex insertion with a moist symmetric vortex during ET), we feel that the level of agreement between the model and QuikSCAT image shown in Figure 4 is actually surprisingly good.

\section{Ocean Model Results}

[20] The barotropic ocean model uses the same grid as the $3-\mathrm{km}$ atmospheric model (Figure 1, dashed box) and is initialized at 0900 UTC 25 September 2000 with zero velocity and zero adjusted sea level. The model is integrated for $18 \mathrm{~h}$ with atmospheric pressure and surface wind forcing input every $5 \mathrm{~min}$. It should be noted that it is necessary to input the atmospheric forcing at a sufficiently high frequency for the ocean model to adequately capture the correct response (this issue is discussed in detail in Appendix A).

[21] As Tropical Storm Helene moves toward the Grand Banks of Newfoundland, there is almost no adjusted sea level response because of the large water depth (the gravity wave speed $\sqrt{g H}$ is much greater than the translation speed of the storm). As the tropical storm starts moving over the southwestern portion of the Grand Banks, an area of adjusted sea level rise develops ahead of the storm (Figure 5a) and then moves with the storm across the Grand Banks with a rise in sea level of over $20 \mathrm{~cm}$ (Figures $5 \mathrm{~b}$ and $5 \mathrm{c}$; the storm translation speed is now comparable to $\sqrt{g H}$ ). The rise in adjusted sea level is caused by the area of convergence in the wind stress ahead and just to the left of the storm center noted when discussing Figure 3f. Both wind (Figure 6a) and pressure (Figure 6b) play a role in generating the adjusted sea level response, although at the time shown in Figure 6 the wind forcing is the dominant effect. The pressure forced response (Figure 6b) is considerably more asymmetric about the storm track than that of Mercer et al. [2002, Figure 6] because of the asymmetries in the pressure field taken from the atmospheric model.

[22] Once the tropical storm reaches the eastern side of the Grand Banks (Figure 5d), a large area of depression in 


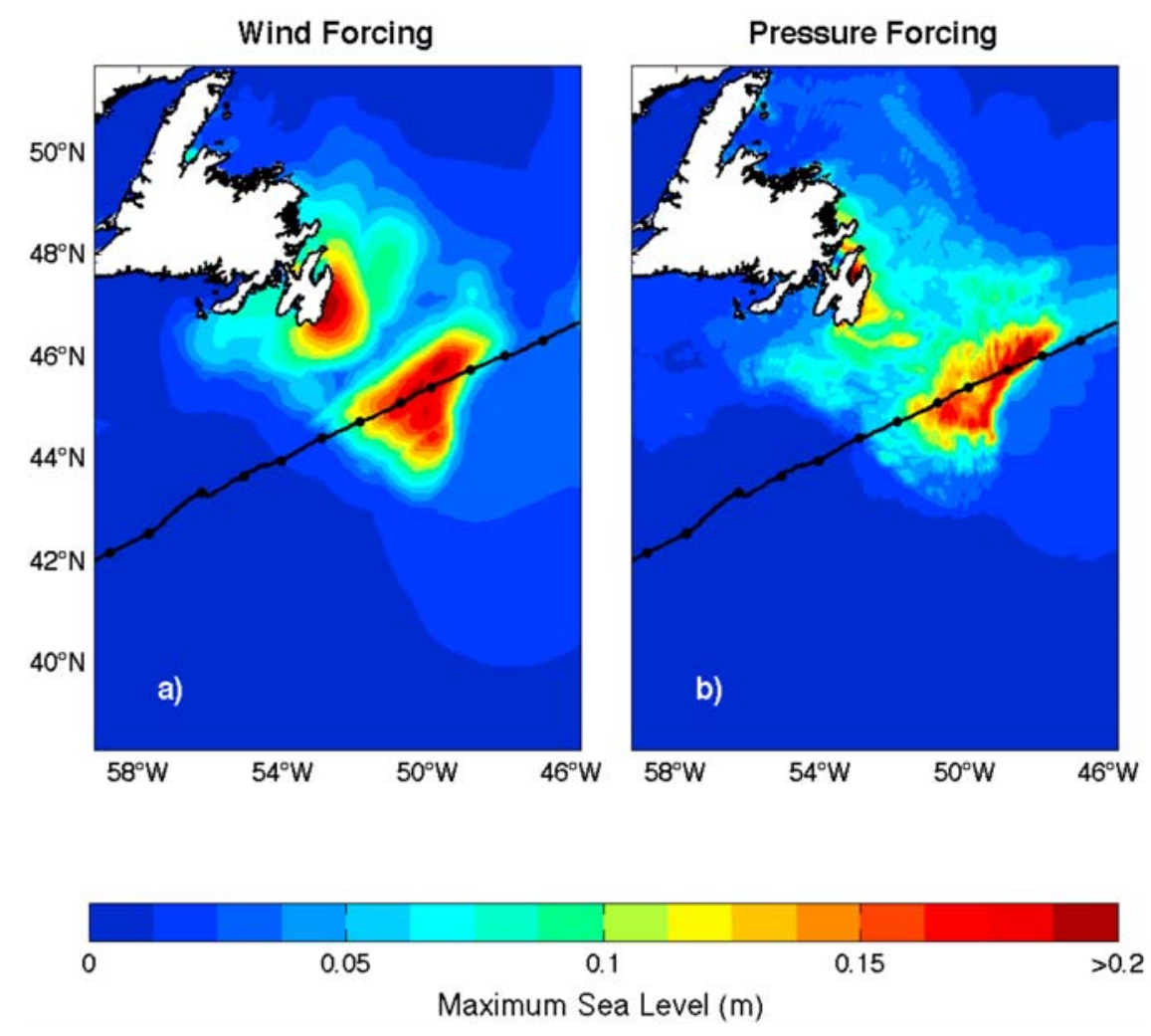

Figure 7. The maximum upward displacement in adjusted sea level from the reference sea level due to (a) wind forcing only and (b) pressure forcing only. The solid black line represents the storm track with hourly storm positions marked by solid dots.

adjusted sea level covering the majority of the Grand Banks starts to form (Figures $5 \mathrm{e}$ and $5 \mathrm{f}$ ). This large area of depressed sea level, by more than $30 \mathrm{~cm}$ compared to the reference sea level, is a consequence of the wind forcing and is refracted toward the Avalon Peninsula (Figures 5e-5i), to be followed by an area of rise in the adjusted sea level of around $20 \mathrm{~cm}$ above equilibrium near the Avalon Peninsula itself (Figures $5 \mathrm{j}$ and $5 \mathrm{k}$ ). Both these features are consequences of wind forcing. Switching the wind forcing off at $11 \mathrm{~h}$ does not lead to significant changes in the wind-forced response implying that much of the drop in sea level over the Grand Banks starting around $11 \mathrm{~h}$, and the subsequent rise along the Avalon Peninsula starting at $16 \mathrm{~h}$, is part of the adjustment process to earlier forcing.

[23] Figure 7 shows the maximum upward displacement in adjusted sea level (relative to the reference sea level) obtained during the model simulation using wind forcing only (Figure 7a) and atmospheric pressure forcing only (Figure 7b). Figure 7 shows the importance of the wind forcing for the model response near the coast of the Avalon Peninsula, while the large rise in sea level in Conception Bay is caused by pressure forcing only (Figure 7b). Offshore, on the Grand Banks, the comparison shows that pressure forcing is equally as important as wind forcing for determining the maximum upward displacement. Note that even though the model is linear, the sum of Figures $7 \mathrm{a}$ and $7 \mathrm{~b}$ does not give the maximum upward displacement to the total forcing since the maxima due to wind and pressure forcing separately do not occur at the same time.

\subsection{Comparison With Tide Gauge Data}

[24] During Tropical Storm Helene there were two active tide gauges on the Avalon Peninsula of Newfoundland, one at Argentia and the other at Saint John's (Figure 8). Data from the tide gauges are available every $15 \mathrm{~min}$. The sea level data were processed using the MATLAB program known as t_tide [Pawlowicz et al., 2002] to remove the tidal harmonics leaving the observed nontidal sea levels. Since the horizontal resolution of the ocean model is not fine enough to resolve the coastal regions accurately, the model wet points closest to the tide gauges were used for assessment of the model performance (Figure 8). The model-calculated nontidal sea levels at Port Rexton, Holyrood, and Bay Bulls were also considered in the analysis. The tide gauge data were shifted $1.75 \mathrm{~h}$ later than observed to eliminate the error in the timing of the simulated storm produced by the atmospheric model. Note that time in Figure 9 is model simulation time with $0 \mathrm{~h}$ corresponding to the time the $3-\mathrm{km}$ atmospheric model is initiated, and it corresponds to the time shown in Figure 5.

[25] At Port Rexton, the model results show that after about $14 \mathrm{~h}$ there are variations in the sea level for which the atmospheric pressure forcing is clearly important (Figure 9). Similar behavior is also found at Holyrood, starting with the drop in sea level around $14 \mathrm{~h}$, followed by a sharp rise in sea level of about $20 \mathrm{~cm}$ at $17.25 \mathrm{~h}$ that is attributable only to pressure forcing. It should be noted that these variations are dominated by the adjusted sea level, the inverse barometer effect playing a minor role. From Figure 10 we see that a rise in sea level coming in from the Grand Banks at about 


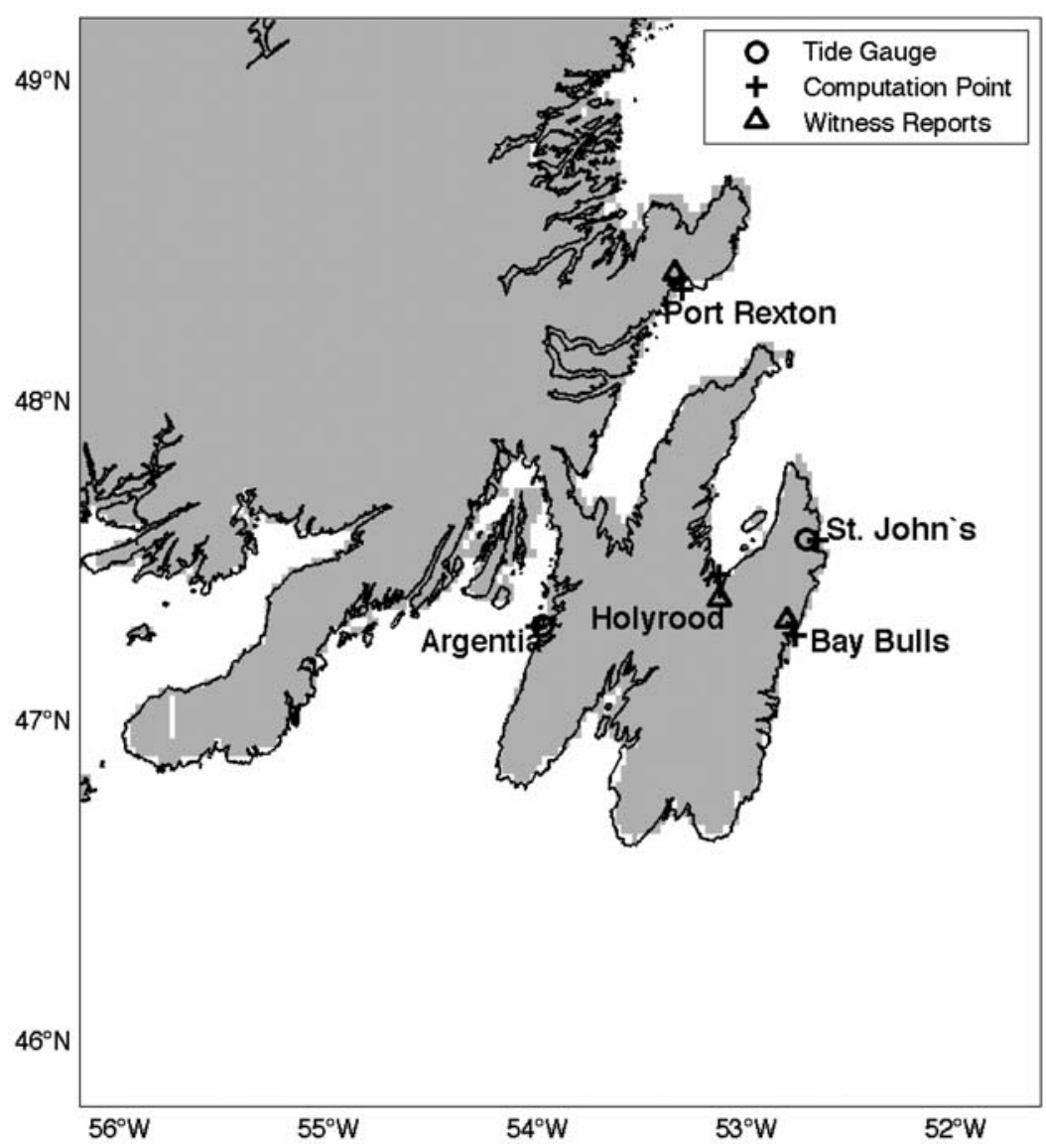

Figure 8. Location of tide gauges (circles) along the southeastern coastline of Newfoundland that were active during Tropical Storm Helene (2000). Also shown are the locations of the eyewitness reports (triangles) and the locations of the model grid points used for model data comparison (crosses).

$15.25 \mathrm{~h}$ (Figure 10b) makes its way toward the Avalon Peninsula and mainly propagates southward along the coast (Figures $10 \mathrm{~b}-10 \mathrm{e}$ ), although part of this rise in sea level moves northward and is responsible for the rise in sea level at Port Rexton and Holyrood between 15.5 and $16 \mathrm{~h}$ (Figure 9). Later, a second rise in sea level moves from the Grand Banks toward the coast (Figures 10f-10j), leading to the large rise in sea level in Conception Bay and, consequently, the spike in sea level of about $20 \mathrm{~cm}$ at Holyrood at $17.25 \mathrm{~h}$. Similarly, there is also a spike in sea level at Port Rexton, occurring slightly later at about $17.5 \mathrm{~h}$. Eyewitnesses reported that a large rise in sea level at Holyrood did indeed occur.

[26] The simulated total sea level time series at Saint John's and Bay Bulls are quite similar (Figure 9) because of the proximity of their location on the Avalon Peninsula. At Saint John's the model captures the events in the observations, although the spikes in the observed record do not show up as sharply in the model. In the model there is a period of depression in sea level $(\sim 5 \mathrm{~cm})$ at Saint John's and Bay Bulls until $6 \mathrm{~h}$ followed by a rise in sea level to about $10 \mathrm{~cm}$ above the reference at around $10 \mathrm{~h}$. The minimum in modeled sea level at Saint John's and Bay Bulls (about $\sim 20 \mathrm{~cm}$ below reference) occurs at around $14 \mathrm{~h}$ (Figure 9), corresponding to the large drop in sea level across the whole of the Grand Banks evident from Figure 5h. At Saint John's and Bay Bulls this drop in sea level is an effect of the combination of both the wind and pressure forcing. The large drop at Saint John's and Bay Bulls matches with the drop in sea level seen at Port Rexton and Holyrood at approximately the same time and is followed by two peaks of up to $20 \mathrm{~cm}$ above the reference sea level separated by about an hour (Figure 9), corresponding to the anomalously high sea level close to the Avalon Peninsula in Figures $5 \mathrm{j}$ and $5 \mathrm{k}$. Both rises in sea level are features of the observed record at Saint John's and in the model occur slightly earlier (by about $5 \mathrm{~min}$ ) at Saint Johns (Figures 10c and $10 \mathrm{~g}$ ) than at Bay Bulls (Figures $10 \mathrm{~d}$ and 10k). The first peak in the sea level $(\sim 15.75 \mathrm{~h})$ is solely a wind-driven phenomenon, while the second peak $(\sim 16.75 \mathrm{~h})$ is mainly an effect of the pressure forcing (Figure 9). These two peaks in sea level are caused by the same incoming signals from the Grand Banks at $15.5 \mathrm{~h}$ (Figure 10b) and $16.5 \mathrm{~h}$ (Figure 10f) that are responsible for the rises in sea level at Port Rexton and Holyrood described earlier. From Figure $10 \mathrm{f}$ we see that the drop in sea level between the two peaks at Saint John's and Bay Bulls is confined to a narrow region of reduced sea level that propagates southward along the coast of the Avalon Peninsula (Figures $10 \mathrm{f}$ and $10 \mathrm{~g}$ ).

[27] At Argentia the ocean model results show a drop in sea level of $\sim 10 \mathrm{~cm}$ between 13.5 and $16.5 \mathrm{~h}$ which is also present in the observational data (Figure 9). Starting at around $16 \mathrm{~h}$, the tide gauge data and the model results show a rising tendency in the sea level, although the model only captures about half the observed rise. In the model these features are caused mostly by the wind forcing, with the 


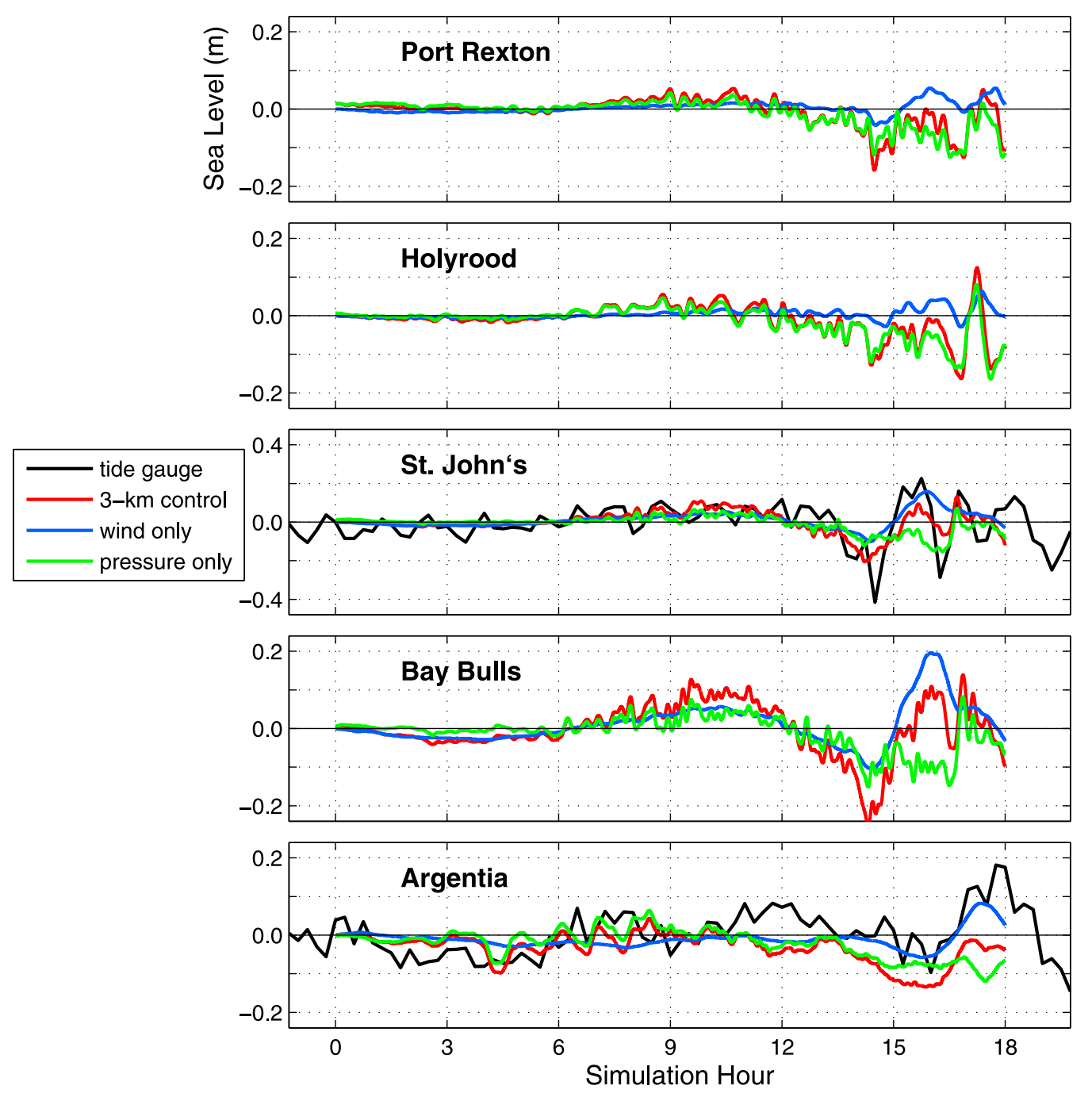

Figure 9. Comparison of nontidal sea level observations (black lines) with model-calculated total sea level (red lines). The contributions generated by wind forcing only (blue lines) and pressure forcing only (green lines) are also shown. The tide gauge data are shifted $1.75 \mathrm{~h}$ on the basis of the fact that the simulated storm is $1.75 \mathrm{~h}$ behind observations. The scale on the plot for Saint John's is double that used at the other locations.

pressure forcing leading to a negative offset not found in the observations. The rise in sea level starting at about $16 \mathrm{~h}$ at Argentia can be traced back to the rise in sea level which propagates in from the Grand Banks at about $15.5 \mathrm{~h}$ and then moves in a clockwise direction around the Avalon Peninsula and arrives at Argentia at $17 \mathrm{~h}$ (Figures 10b-10h).

[28] To quantize the agreement between the model and the observed data, we can define a skill score, $\gamma$, by the ratio of the averaged squared difference between the model and the observations to the variance in the observations. Perfect agreement between the model and observations then gives a skill score of 0 , whereas running a model with no sea level response at the coast gives a skill score of 1 . To compute $\gamma$, we use the $6 \mathrm{~h}$ from 12 to $18 \mathrm{~h}$ in Figure 9, and for each time series (model and observations) the mean over the 6 -h period is removed before the analysis. For the observed time series, linear interpolation is used between the 15-min intervals when data are available. The computed skill scores for Saint John's and Argentia are 0.6 at both locations. For comparison, the skill scores using the model at Argentia and obser- vations at Saint John's, and vice versa, are 1.1 and 2.9, respectively. It should be remembered, however, when comparing the model with the observations that the atmospheric model that is used to provide the forcing for the ocean model is initialized in a very simple way by means of the insertion of a moist symmetric vortex. Given the simplicity of the initialization procedure, the level of agreement between the ocean model and the observations is actually surprisingly good. It should also be noted that the ocean model does not resolve the details of the coastline where the tide gauges are located and therefore cannot capture seiches and other local effects that can be present in the observations.

\subsection{Sensitivity to the Storm Track Position}

[29] The location of the storm track is a discrepancy in the atmospheric model simulation of Tropical Storm Helene compared to the observations. The storm track is farther south than observed by $\sim 0.4^{\circ}$ in latitude (Figure 1). Since Mercer et al. [2002] showed that the barotropic model results are sensitive to the location of the storm track over the Grand 

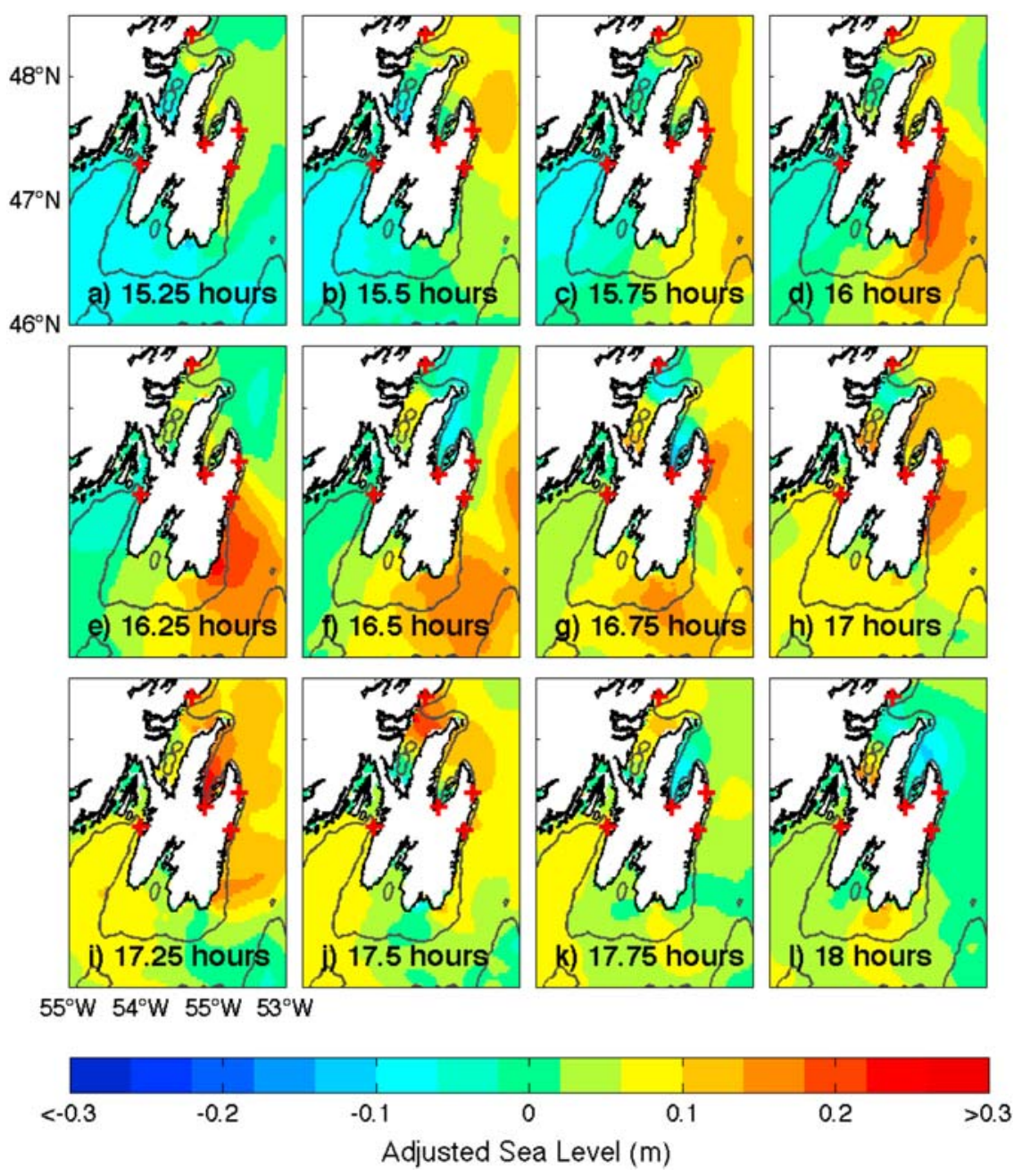

Figure 10. Time series of model-calculated adjusted sea level zoomed in on the Avalon Peninsula region for both wind and pressure forcing combined. The red crosses give the locations of the closest model wet points to the tide gauges/eyewitness reports (see Figure 8 for more details), and the dark gray lines give the $100-, 500-$, and 1000-m depth contours. The time is given in hours from simulation start time with a separation of $0.25 \mathrm{~h}$ between each plot.

Banks, two numerical experiments were conducted with the initial position of the synthetic vortex in the atmospheric model perturbed to the north by $0.3^{\circ}$ (experiment HN1) and $0.6^{\circ}$ (experiment $\mathrm{HN} 2$ ) in latitude (Table 1). The results from the ocean model driven by output from the two atmospheric model experiments are compared with those in the control run (HCR).

[30] The modeled storms with the more northern initial positions both have a storm track which is farther to the north than the control run but still south of the storm track according to the observations (Figure 11). The timing of the HN1 and HN2 storms matches the timing of the storm track position in the observations better than the HCR model results. However, the modeled tropical storms in $\mathrm{HN} 1$ and $\mathrm{HN} 2$ are still behind the observations by $\sim 1.25$ and $\sim 1.5 \mathrm{~h}$, respectively.

[31] Because of the differences in timing of the modeled storms in HCR, HN1, and HN2, the time shift used to compare the experiments with the tide gauge data differs for each case. At Bay Bulls and Saint John's the results from all three experiments show some minor differences
(Figure 12), for example, the relative timing and magnitude of the dip in sea level around $16.5 \mathrm{~h}$. The greatest difference among the three experiments occurs at Holyrood, where there is a large spike at $17.25 \mathrm{~h}$ in HCR which is not present in either HN1 or HN2 (Figure 12). From other studies, it was shown that the generation of local seiches in bays and harbors is sensitive to the angle of incidence of the wave, and this in turn is influenced by the storm track. The differences among model experiments at Holyrood are a good example of this phenomenon. Since the modeled storms in HN1 and HN2 track a bit closer in time to the observations, the atmospheric model forcing is available long enough for the ocean model to detect the drop in sea level at Argentia after $17 \mathrm{~h}$ (Figure 12) in these experiments.

\section{Summary and Conclusions}

[32] The dynamic ocean response to Tropical Storm Helene (2000) has been studied using a barotropic shallow water ocean model forced by output from a nested grid atmospheric circulation model. Despite Tropical Storm Helene not being an 


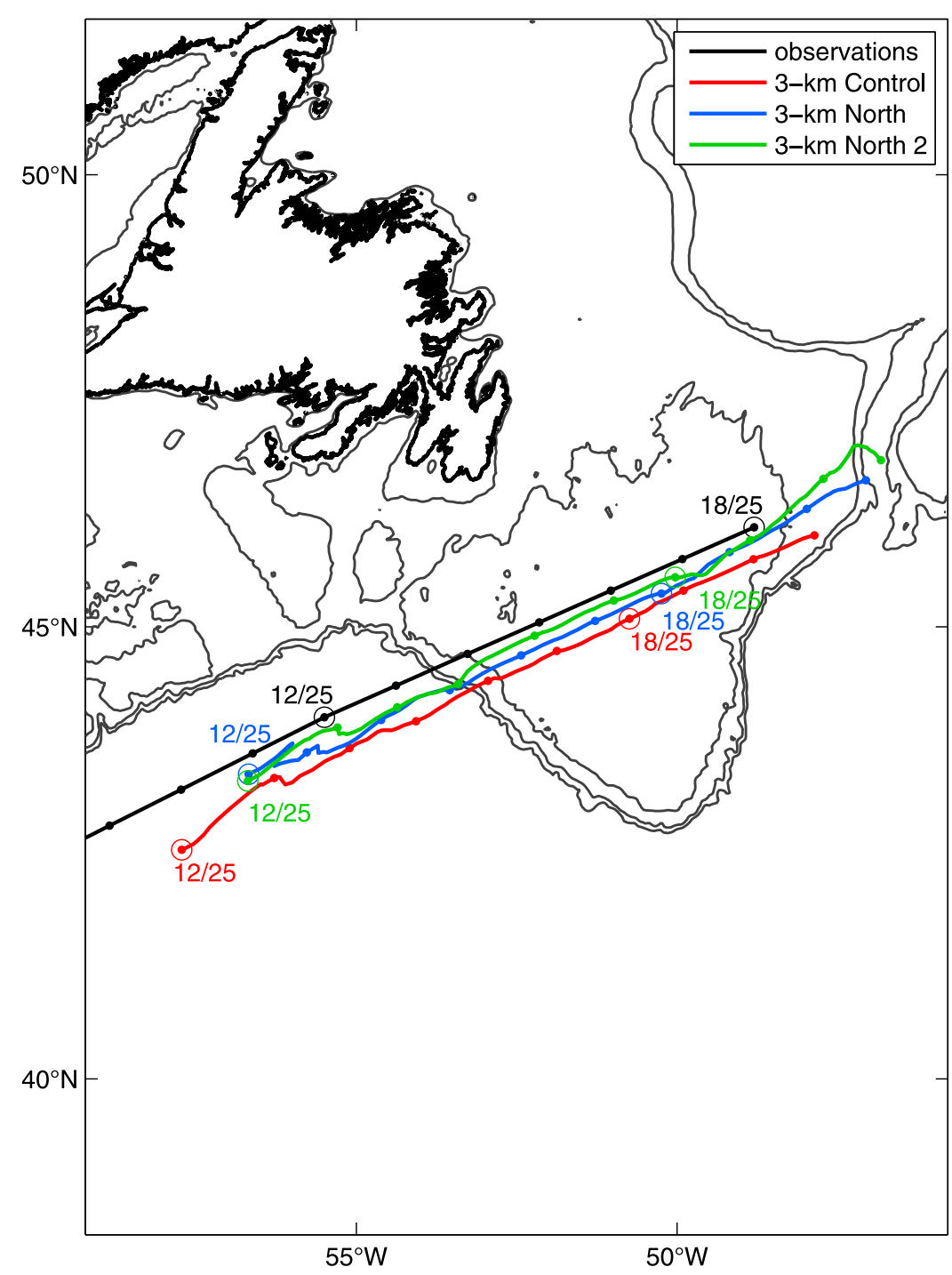

Figure 11. Simulated storm tracks for Tropical Storm Helene (2000) for all three atmospheric model experiments. The black line shows the observed track for Tropical Storm Helene [Blake and Avila, 2000], the red line is the storm track from HCR, the blue line is the storm track from HN1, and the green line is the storm track from HN2 with time given in HH/DD UTC. The 100-, 500-, and 1000-m bathymetry contours are shown along with the coast line.

ideal candidate for the synthetic vortex insertion, the atmospheric model is able to simulate the storm much better than the operational numerical weather prediction model. The major issue with the atmospheric model results is the timing of the storm; in the control run the storm is $1 \mathrm{~h} 45 \mathrm{~min}$ behind the observed storm. Another issue is that the modeled storm tracks too far south over the Grand Banks. Nevertheless, the atmospheric model is able to capture the frontal features present in the observed atmospheric fields and the area of high winds to the right of the storm track.

[33] The ocean model, forced by sea level pressure and surface winds derived from the atmospheric model output, shows a rise in adjusted level of up to $20 \mathrm{~cm}$ over the Grand Banks associated with an area of wind stress convergence in the front left quadrant near the center of the storm. This is followed by a reduction of adjusted sea level over the Grand Banks of up to $50 \mathrm{~cm}$ that is subsequently refracted along the northern edges of the Grand Banks toward the Avalon Peninsula of Newfoundland and is followed, in turn, by a strong rise in adjusted sea level near the Avalon Peninsula. Much of the drop in the sea level over the Grand Banks and subsequent rise near the Avalon Peninsula is not directly forced but is a consequence of the ocean adjustment to the earlier forcing. When comparisons are made with tide gauge observations at Saint John's and Argentia, Newfoundland, the ocean model results capture the sequence of the events and show the importance of wind stress and atmospheric pressure forcing for explaining the impact of the storm at the coast. By comparison to wind forcing, the atmospheric pressure-driven response at the coast is generally less important (an exception being Conception Bay) but plays a more important role offshore.

[34] Because of the rapid translation speed of Tropical Storm Helene it is very important to have fine temporal resolution for the atmospheric forcing (see Appendix A). Moving the initial position of the storm used in the synthetic vortex insertion farther north in order to attempt to match the simulated storm track closer to the observations improved the 

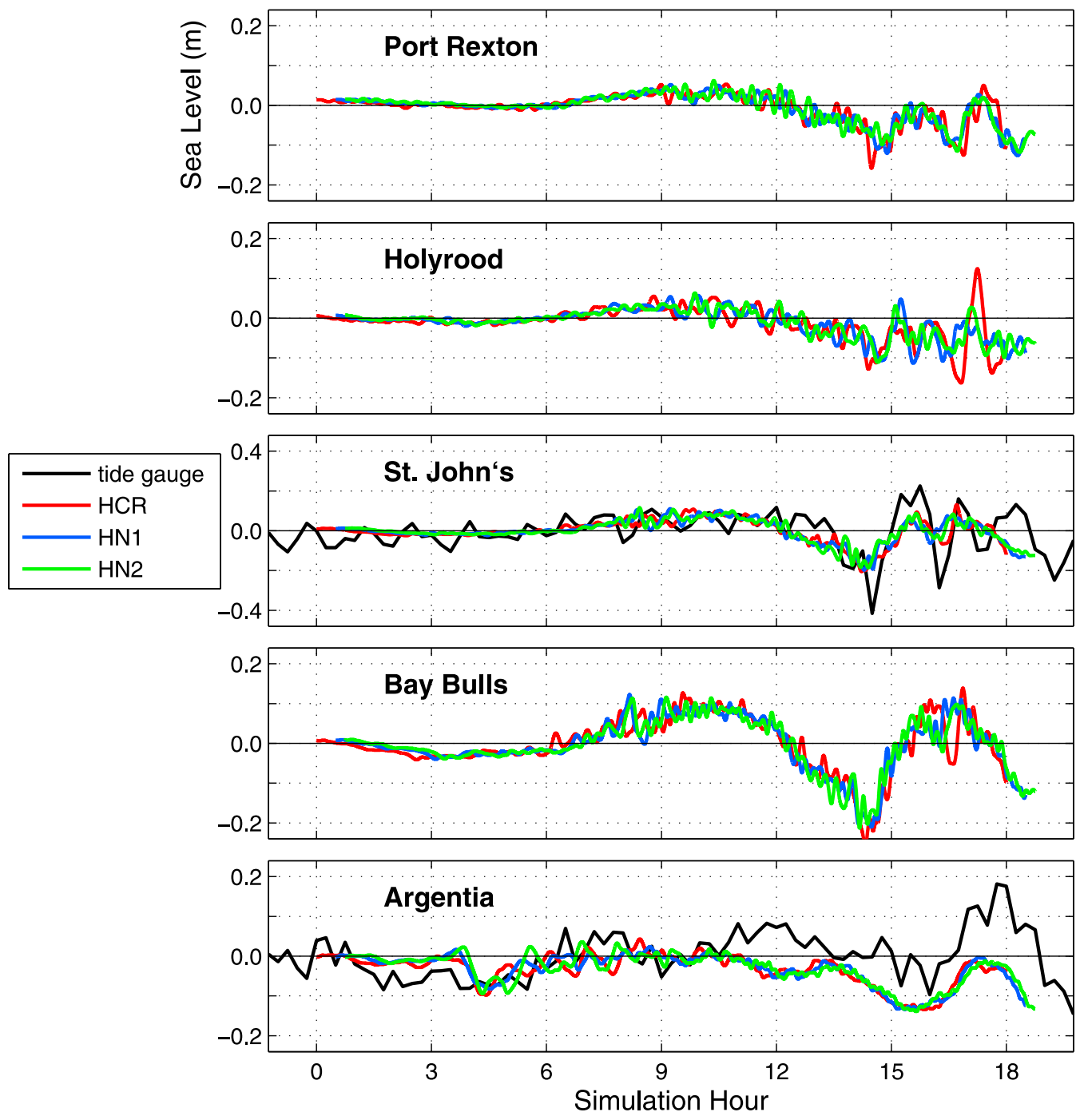

Figure 12. Comparison of nontidal sea level observations (black) with model results in experiments HCR (red lines), HN1 (blue lines) and HN2 (green lines) for Tropical Storm Helene. The tide gauge data are shifted by $1.75 \mathrm{~h}$, and the model data are shifted by $0.5 \mathrm{~h}$ in HN1 and $0.75 \mathrm{~h}$ in HN2 to match the timing of the HCR experiment. The scale on the plot for Saint John's is double that for the other locations. 
a)

$$
\mathrm{t}=0
$$

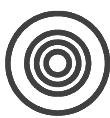

$\mathrm{t}=\frac{1}{4} \mathrm{dt}_{i n}$

b)

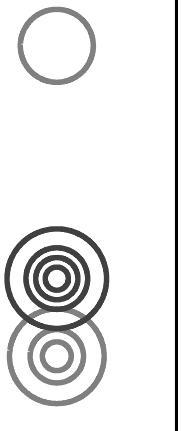

$\mathrm{t}=\frac{1}{2} \mathrm{dt}_{i n}$

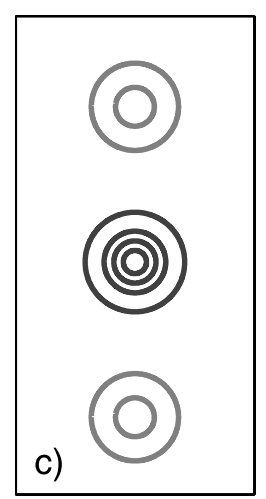

$\mathrm{t}=\frac{3}{4} \mathrm{dt}_{i n}$

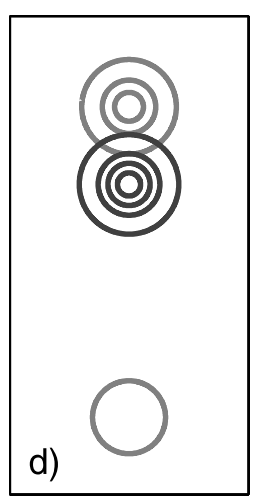

$\mathrm{t}=\mathrm{dt}_{i n}$

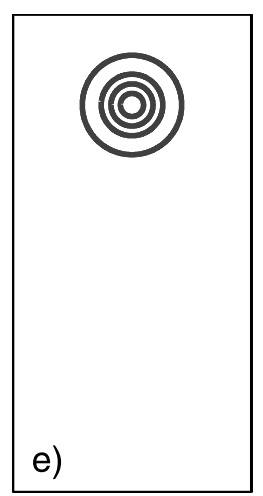

Figure A1. Schematic showing the actual (dark gray) and interpolated (light gray) pressure fields of a storm as it moves northward. The atmospheric forcing is computed at a time interval of $d t_{i n}$, while the ocean model time step is, in this case, $d t_{i n} / 4$.

timing of the storm to just over $1 \mathrm{~h}$ behind that in the observations. The simulated ocean response to the atmospheric forcing generated in these cases shows some differences from the control model results, but these are generally minor with one major exception. In Conception Bay the pressure-generated sea level rise is about half of what is present in the control run, and hence, at Holyrood, which is in the southern tip of Conception Bay, the large sea level rise is not as strong as in the control run.

[35] Overall, the ocean model results have shown the importance of having a combination of both wind stress and atmospheric pressure forcing in the calculation of the sea level response to Tropical Storm Helene. Our study has shown that creating a system which uses a barotropic ocean model driven by atmospheric forcing derived from an atmospheric model simulation has potential as a tool to aid in forecasting the sea level response to future events similar to Tropical Storm Helene.

\section{Appendix A: Linear Interpolation of Atmospheric Forcing Data}

[36] In this study, the atmospheric model is run independently prior to the integration of the ocean model. Because of the limitations of computation power and storage it is not practical to read the atmospheric forcing at each time step of the ocean model. However, the atmospheric forcing is still required at each computational time step of the ocean model. To solve this problem, Bobanović and Thompson [2001] successfully used linear interpolation of the atmospheric forcing to each time step of the ocean model. When the barotropic ocean model reads the atmospheric fields, the ocean model initially sees the storm in the same location as the actual storm (Figure A1a). Similarly, the next time the ocean model reads in the atmospheric fields, the ocean model sees the storm in the correct position (Figure A1e). However, between the times when atmospheric data are input, the ocean model sees two weaker stationary storms with a higher minimum sea level pressure (Figures $\mathrm{A} 1 \mathrm{~b}-\mathrm{A} 1 \mathrm{~d}$ ) as opposed to one translating storm. Having two weaker storms can cause the ocean response to be smaller than it would have been if there were continuous input from the atmospheric model and can change the structure of the sea level response. Figure A1 illustrates an extreme case in which the tropical cyclone moves many grid lengths between the atmospheric forcing inputs.

[37] An ocean model with horizontal resolution of $\Delta x$ would have a tropical cyclone with a translational speed of $U$ traverse a grid box in a time $T \approx \Delta x / U$. This suggests that an interval of $d t_{i n} \leq \Delta x / U$ should be used for the atmospheric forcing to the ocean model. For this study in this paper, where the ocean model has a resolution of $\Delta x \approx 3 \mathrm{~km}$, this suggests $d t_{\text {in }} \leq 2 \mathrm{~min}$ for Tropical Storm Helene $\left(U \approx 26 \mathrm{~m} \mathrm{~s}^{-1}\right)$.

[38] Numerical experiments were made to examine the sensitivity of the model results to the time step of the atmospheric pressure forcing associated with a rapid moving, tight, idealized tropical cyclone. The idealized pressure forcing is represented as [Mercer et al., 2002]

$$
p_{\text {ideal }}(x, y, t)=p_{o}-\Delta p \exp \left[-\frac{\left[x-x_{s}(t)\right]^{2}+\left[y-y_{s}(t)\right]^{2}}{\sigma^{2}}\right],
$$

where $\left(x_{s}(t), y_{s}(t)\right)$ is the storm center location, $\sigma$ is a measure of the size of the storm, $p_{o}$ is the background pressure, and $\Delta p$ is the pressure drop in the storm. For simplicity, we used $\Delta p=$ $30 \mathrm{hPa}$ and $\sigma=40 \mathrm{~km}$ moving with a forward translational speed of $31 \mathrm{~m} \mathrm{~s}^{-1}$ over a flat-bottomed ocean with a depth of $100 \mathrm{~m}$. The ocean model was then run using input time steps for the atmospheric forcing varying from forcing every ocean model time step to 3-hourly forcing (currently used in the operational ocean model). For each case, the ocean model output is compared to the case in which the atmospheric forcing is given to the ocean model every ocean model time step. The maximum upward displacement from equilibrium in sea level attained for each case is considered (Figure A2a), as well as the maximum downward displacement from equilibrium in sea level attained (Figure A2b) for both the adjusted sea level and total sea level. The maximum difference between having atmospheric forcing at each ocean model time step and only at specific time steps is also compared for both the total sea level and adjusted sea level (Figure A2c). 

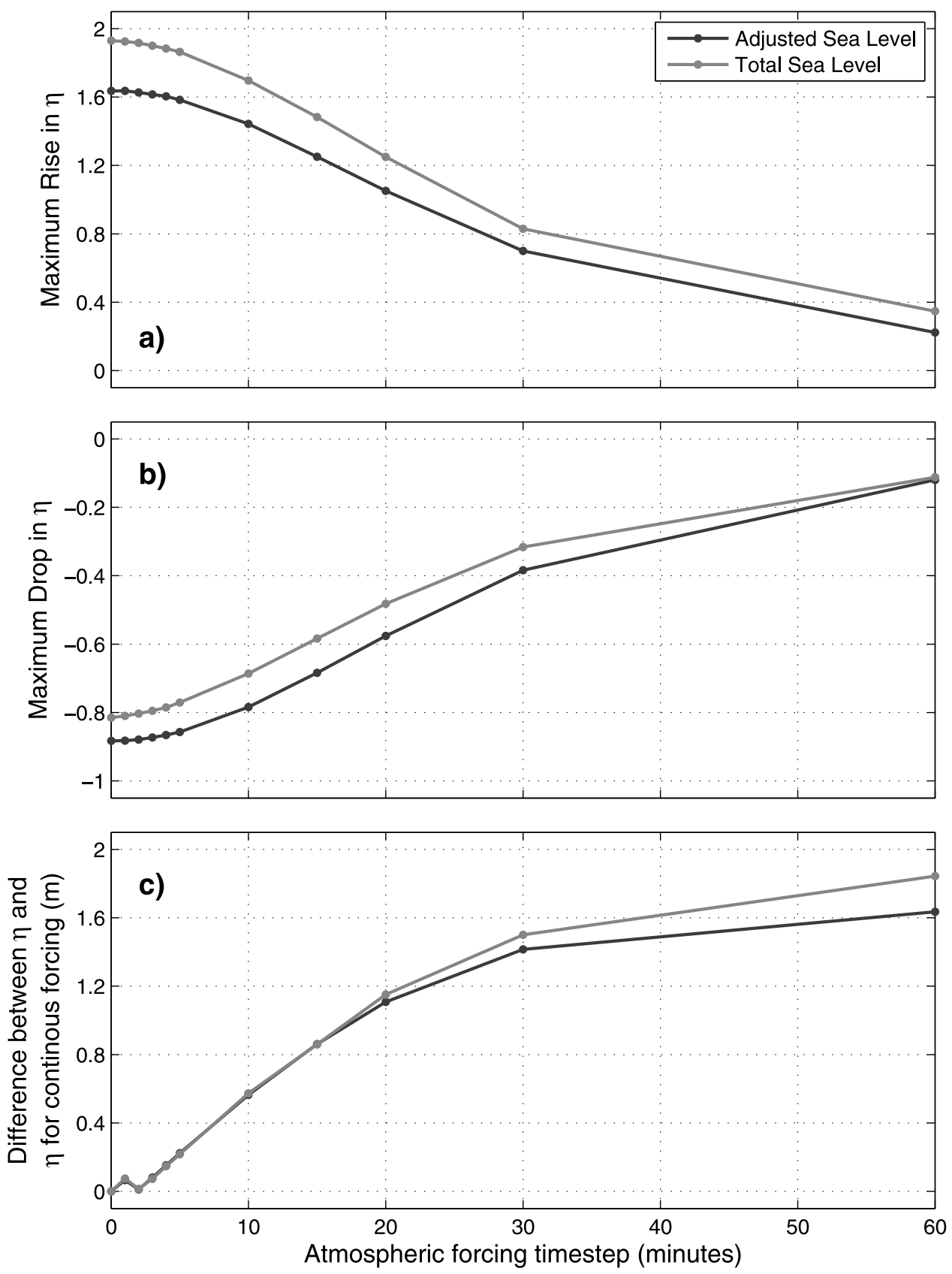

Figure A2. Sensitivity of the ocean model results to the frequency of atmospheric forcing input. (a) The maximum upward displacement and (b) the maximum downward displacement in sea level from equilibrium are shown in meters for different atmospheric forcing time steps for both adjusted (dark gray) and total sea level (light gray). (c) The maximum difference between cases with a set atmospheric pressure forcing interval and the case with atmospheric pressure forcing every ocean model time step for adjusted (dark gray) and total sea level (light gray).

[39] Inputting the atmospheric pressure forcing at intervals longer than $1 \mathrm{~h}$ leads to a model performance similar to that when the atmospheric forcing time step is hourly. The maximum upward displacement in sea level in these cases is less than $\sim 20 \%$ of that having atmospheric forcing every ocean model time step for both total sea level and adjusted sea level (Figure A2a). Similarly, the maximum downward displacement in sea level for 1-hourly atmospheric forcing is only $\sim 15 \%$ of that when the atmospheric pressure forcing is provided every ocean model time step (Figure A2b).
Furthermore, the maximum difference between the case with hourly forcing input and forcing every time step is over $1.6 \mathrm{~m}$ for both the adjusted sea level and total sea level (Figure A2c).

[40] As the atmospheric forcing is provided more frequently, the model results converge toward the case with atmospheric forcing at every ocean model time step. When the ocean model has atmospheric pressure forcing at every $2 \mathrm{~min}$ the response is within a few percent of when the ocean model receives the forcing every ocean model time step. For comparison, the time it takes the tropical storm to traverse 
one grid box of $\Delta x / U \approx 1.6 \mathrm{~min}$. For slower moving storms, one can use atmospheric forcing with a larger time interval.

[41] Acknowledgments. Funding for this project came from the NSERC/MARTEC/MSC Industrial Research Chair held jointly by R.J.G. and J.S. We would also like to thank the CMC for allowing the use of their computer facility for the atmospheric model runs. QuikSCAT data were produced by Remote Sensing Systems and sponsored by the NASA Ocean Vector Winds Science Team. Data are available at http://www.remss.com. The tide gauge data are available from the Marine Environmental Data Service of the Department of Fisheries and Oceans, Canada, at http:// www.meds-sdmm.dfo-mpo.gc.ca. Comments from anonymous reviewers were helpful for improving the manuscript.

\section{References}

Benoit, R., M. Desgagné, P. Pellerin, S. Pellerin, Y. Chartier, and S. Desjardins (1997), The Canadian MC2: A semi-Lagrangian, semiimplicit wideband atmospheric model suited for finescale process studies and simulation, Mon. Weather Rev., 125(10), 2382-2415, doi:10.1175 1520-0493(1997) $125<2382$ :TCMASL $>2.0$. CO;2.

Blake, E., and L. Avila (2000), Tropical cyclone report for Tropical Storm Helene: 12-25 September 2003, report, Natl. Hurricane Cent., Miami, Fla.

Bobanović, J., and K. Thompson (2001), The influence of local and remote winds on the synoptic sea level variability in the Gulf of Saint Lawrence, Cont. Shelf Res., 21(2), 129-144, doi:10.1016/s0278-4343(00)00079-0.

Bobanović, J., K. Thompson, S. Desjardins, and H. Ritchie (2006), Forecasting storm surge along the east coast of Canada and the north-eastern United States: The storm of 21 January 2000, Atmos. Ocean, 44(2), 151-161, doi:10.3137/ao.440203.

Carter, G., and M. Merrifield (2007), Open boundary conditions for regional tidal simulations, Ocean Modell., 18(3-4), 194-209, doi:10.1016 j.ocemod.2007.04.003.

Donelan, M., W. Drennan, and K. Katsaros (1997), The air-sea momentum flux in conditions of wind sea and swell, J. Phys. Oceanogr., 27(10), 2087-2099, doi:10.1175/1520-0485(1997)027<2087:TASMFI $>2$. $\mathrm{CO} ; 2$.
Donelan, M. A., B. K. Haus, N. Reul, W. J. Plant, M. Stiassnie, H. C. Graber, O. B. Brown, and E. S. Saltzman (2004), On the limiting aerodynamic roughness of the ocean in very strong winds, Geophys. Res. Lett., 31, L18306, doi:10.1029/2004GL019460.

Fogarty, C., R. Greatbatch, and H. Ritchie (2006), The role of anomalously warm sea surface temperatures on the intensity of Hurricane Juan (2003) during its approach to Nova Scotia, Mon. Weather Rev, 134(5), 1484-1504, doi:10.1175/MWR3140.1.

Fogarty, C., R. Greatbatch, and H. Ritchie (2007), The use of a vortex insertion technique to simulate the extratropical transition of Hurricane Michael (2000), Weather Forecast., 22(3), 480-500, doi:10.1175/ WAF1014.1.

Gill, A. (1982), Atmosphere-Ocean Dynamics, 662 pp., Academic, San Diego, Calif.

Large, W., and S. Pond (1981), Open ocean momentum flux measurements in moderate to strong winds, J. Phys. Oceanogr., 11(3), 324-336, doi:10.1175/1520-0485(1981)011<0324:OOMFMI >2.0.CO;2.

Mercer, D., J. Sheng, R. Greatbatch, and J. Bobanovic (2002), Barotropic waves generated by storms moving rapidly over shallow water, J. Geophys. Res., 107(C10), 3152, doi:10.1029/2001JC001140.

Pawlowicz, R., B. Beardsley, and S. Lentz (2002), Classical tidal harmonic analysis including error estimates in MATLAB using T_TIDE, Comput. Geosci., 28(8), 929-937, doi:10.1016/S0098-3004(02)00013-4.

Powell, M., P. Vickery, and T. Reinhold (2003), Reduced drag coefficient for high wind speeds in tropical cyclones, Nature, 422(6929), 279-283, doi:10.1038/nature01481.

Yelland, M., and P. Taylor (1996), Wind stress measurements from the open ocean, J. Phys. Oceanogr., 26(4), 541-558, doi:10.1175/15200485(1996)026<0541:WSMFTO >2.0.CO;2.

C. T. Fogarty, Canadian Hurricane Center, Environment Canada, 45 Alderney Drive, Dartmouth, NS B2Y 2N6, Canada.

R. J. Greatbatch and J. V. Mecking, Leibniz Institute of Marine Sciences at University of Kiel (IFM-GEOMAR), Dürsternbrooker Weg 20, D-24105 Kiel, Germany. (jmecking@ifm-geomar.de)

D. Mercer, Environment Canada, 45 Alderney Drive, Dartmouth, NS B2Y 2N6, Canada.

J. Sheng, Department of Oceanography, Dalhousie University, 1355 Oxford Street, Halifax, NS B3H 4J1, Canada. 